\title{
Estimation of genetic parameters for growth related traits at different stages of development in Paralichthys olivaceus (Temminck \& Schlegel, 1846)
}

\author{
F. LIU ${ }^{1,2,3}$, S. L. CHEN ${ }^{2,3}$, L. WANG ${ }^{2,3,4}$, Y. P. ZHANG ${ }^{2,3}$, Y. S. TIAN ${ }^{2,3}$ AND H. L. CHEN $^{2,3,5}$ \\ ${ }^{1}$ Marine and Fishery Research Institute of Zhejiang Ocean University, Zhoushan - 316 021, China \\ ${ }^{2}$ Key Lab for Sustainable Development of Marine Fisheries, Ministry of Agriculture, Yellow Sea Fisheries Research \\ Institute, Chinese Academy of Fishery Sciences, Qingdao - 266 071, China \\ ${ }^{3}$ Laboratory for Marine Fisheries Science and Food Production Processes, Qingdao National Laboratory for Marine \\ Science and Technology, Qingdao - 266 237, China \\ ${ }^{4}$ College of Fisheries, Henan Normal University, Xinxiang - 453 007, China \\ ${ }^{5}$ College of Fisheries and Life Science, Shanghai Ocean University, Shanghai - 201 306, China \\ e-mail:chensl@ysfri.ac.cn
}

\begin{abstract}
Genetic parameters of growth traits at different growing stages of Paralichthys olivaceus (Temminck and Schlegel, 1846) were estimated using 30 families. The estimates of heritability for body weight at four developmental stages viz., 210, 450, 720 and 830 days of age, varied from 0.12 to 0.37 . The heritability at 720 days of age was the lowest and that of 450 days was the highest. The maternal effect was 0.08 at 210 days, 0.03 at 450 days and almost zero (8.89 E-8 and 2.40 E-7) at 720 and 830 days. Correlation coefficients of the estimated breeding value (EBV) and phenotypic value (PV) of body weight at different developmental stages were $0.470-0.803$, which were highly significant $(p<0.01)$. Correlation of estimated breeding value (EBV) and phenotypic value (PV) was the highest at 210 days of age and the lowest at 720 days. Genetic correlation among the four stages showed large variation (0.339-0.811), which were highly significant except that of 210 and 830 days. The value and accuracy of estimating genetic parameters for growth traits at different stages was different. Therefore, the growth stage should be taken into account when designing a breeding program for growth traits in $P$. olivaceus.
\end{abstract}

Keywords: Breeding value, Growth related trait, Heritability, Paralichthys olivaceus

\section{Introduction}

Paralichthys olivaceus is one of the most important species for mariculture (Liu et al., 2005b), which shows morphological left-right asymmetry (Fan et al., 2015). $P$. olivaceus is widely cultured throughout the coastal areas of north China and the farming of the species is a rapidly growing industry (Song et al., 2012; Yang et al., 2013). As a result of long-term, high-intensity stocking and resource management (Shao et al., 2015), the farming of $P$. olivaceus in China is beset with many serious issues such as poor quality of seed, slow growth and increased susceptibility to diseases. This situation has affected profitability of fish farmers and constrained the development of $P$. olivaceus aquaculture in China (Liu et al., 2005a). In order to render the aquaculture development of $P$. olivaceus healthy and sustainable, it is necessary to breed $P$. olivaceus strains for faster growth.

In aquaculture production, the rate of growth is a critically important economic trait (Liu et al., 2011). The main objective of most selective breeding programs in fish is to enhance the growth rate, which can lead to more efficient fish production (Charo-Karisa et al., 2007). Breeding programs for growth traits in aquaculture typically use the family rearing of fry until the tagging size is reached. Thereafter, the tagged fish are mixed and reared in ponds until broodstock are selected (Blonk et al., 2010). Estimation of genetic parameters is the basis for selective breeding and planning of breeding programmes (Zhang et al., 2011). Genetic parameter estimates for growth-related traits have been reported in certain fish, viz., Dicentrarchus labrax (Karahan et al., 2013), Salmo salar (Guy et al., 2009), Larimichthys crocea (Liu et al., 2013), Oncorhynchus mykiss (Sae-Lim et al., 2013; $\mathrm{Hu}$ et al., 2013), Hypophthalmichthys molitrix (Gheyas et al., 2009), Oreochromis niloticus (Trọng et al., 2013; He et al., 2015), Cyprinus carpio (Ninh et al., 2011) and Labeo rohita (Das Mahapatra et al., 2007). Determination of the estimated breeding values (EBVs) of the breeding candidates and genetic parameters of target traits for captive bred fish at present are commonly based on the restricted maximum likelihood (REML) and best linear unbiased prediction (BLUP).

Liu et al. (2013) estimated the genetic parameters for the growth related traits of $P$. olivaceus (450 days old), based 
on the data collected from 24 families, but they did not study the genetic parameter at different ages. Therefore, the present study, focused on the growth traits of the P. olivaceus, at 210, 450,730 and 830 days of age, which roughly corresponded to the conditions viz., before overwintering, the first growth spurt, after overwintering and the second growth spurt, respectively. Heritability and EBVs of the body weight were estimated based on the data collected from 30 families produced by artificial fertilisation in 2010. We investigated changes in the genetic parameters and EBVs of the body weight of $P$. olivaceus at different ages and analysed the correlation between ages to unravel the relationship between body weight at different growing stages, which can provide important reference material to carry out selective breeding of $P$. olivaceus.

\section{Materials and methods}

Broodfishes for the study were derived from 5 lines: Korea stock (KS) and four selected lines (F0719, F0750, F0751 and F0768) produced in 2007, as described by Tian et al. (2011). All broodfishes were cultured in the Haiyang Aquaculture Breeding Station, Shandong Province, China. Artificial insemination was employed to breed $P$. olivaceus in late April 2010. One male was mated with one/three females (for production of full sibs/paternal half-sibs) and one female also was mated with one/three different males (full sibs/maternal half-sibs). The mating lasted about one month. Fertilised eggs were kept in separate tanks $\left(3 \mathrm{~m}^{3}\right)$ with flow through water. The water temperature of the tanks ranged from 17 to $25^{\circ} \mathrm{C}$ with a salinity of $30-32 \%$. The $\mathrm{pH}$ of seawater was about 7.8. Thirty families were obtained by crossing 25 female and 16 male parents (Table 1) and data on these were analysed. Families were reared separately in tanks. Each tank was stocked with about 1500 fry. Transformed fry from floating to demersal state (about 20 days old) were selected for stocking. When the youngest fry were 80 days old, all families were tagged with Visible Implant Fluorescent Elastomer (VIE) tags. About 150 to 200 individuals were randomly sampled from each family and tagged. In total, 4753 individuals were tagged and stocked randomly in two indoor ponds $\left(40 \mathrm{~m}^{3}\right)$.

Table 1. The breeding design using the five broodstocks along with the No. of family

\begin{tabular}{lllllll}
\hline \multirow{2}{*}{ Female } & \multicolumn{6}{c}{ Male } \\
\cline { 2 - 7 } & F0719 & F0750 & F0751 & F0768 & KS & Total \\
\hline F0719 & 1 & 1 & 2 & 1 & 2 & 7 \\
F0750 & 1 & 1 & & 2 & 1 & 5 \\
F0751 & 1 & 1 & 1 & & 7 & 10 \\
F0768 & & & & 1 & 1 & 2 \\
KS & & 5 & & & 1 & 6 \\
Total & 3 & 8 & 3 & 4 & 12 & 30 \\
\hline
\end{tabular}

\section{Data collection}

Genetic parameters were estimated for the following four growing stages viz., i) before overwintering, when the fish were approximately 210 days and were just in the suitable temperature condition to grow; ii) the first growth spurt, when the fish were approximately 450 days old and were in the suitable temperature condition to grow; iii) after overwintering, when the fish were 720 days old and were in the low temperature condition which slows down growth; and iv) the second growth spurt, when the fish were approximately 830 days old and were in the suitable temperature condition to grow. About 28 - 50 individuals were randomly sampled from each family and the body weight $(\mathrm{g})$ measured. The data thus recorded were used to estimate genetic parameters and predict the estimated breeding value (EBV).

\section{Statistical analysis}

Dataset was analysed using SAS software (SAS, 2011). The variance components of body weight in the four growth stages were estimated using REML and BLUP in the ASReml software (Gilmour et al., 2012). The mixed model applied to analyse the body weight consisted of the fixed effects (the rearing ponds) and random effect (the animal and maternal effect). The full-sib effect included in the model will lead the animal effect variance to be almost zero, and the paternal effect variance was also almost zero. Therefore, the full-sib effect and paternal effect had not been added in the model. Thus, the model was written as:

$$
y=\mu+\text { pond }+ \text { age }+a+m+e
$$

where, $y$ is the vector of body weight; $\mu$ is the overall mean; pond indicates the effect of pond (fixed); age is the age in nimber of days of the family fixed as covariate in the analysis model; $a$ is the random effect of each animal, $a \sim\left(0, A \sigma_{\mathrm{a}}^{2}\right)$, where $A$ is the additive genetic relationship matrix among all individuals, including their parents without data records of body weight; $m$ is the maternal effect, fixed as a random effect and $e$ is the residual effect.

The heritability $\left(h^{2}\right)$ and maternal effect $\left(h_{m}{ }^{2}\right)$ of the body weight within each age group were computed as:

$$
\begin{aligned}
& h^{2}=V_{a} /\left(V_{a}+V_{m}+V_{e}\right) \\
& h_{m}^{2}=V_{m} /\left(V_{a}+V_{m}+V_{e}\right)
\end{aligned}
$$

where, $V_{a}$ is the random effect variance; $V_{m}$ is the maternal effect variance; and $V_{e}$ is the residual variance.

\section{Results and discussion}

\section{Descriptive statistics}

The details of body weights at the four different ages along with the number of family, sampling number from each family and total number of records at each developmental 
age studied are provided in Table 2. As expected, the mean values increased, and the coefficient of variation declined as the fish grew, which means the individual difference in body weight decreased with age. The descriptive statistics of data from ponds are summarised in Table 3 . In the beginning, fish were reared in two ponds, and thereafter divided and stocked into three ponds after the second measurement, to avoid high stocking density and to facilitate growth. Comparison of the mean values of body weight in separate ponds in each growth stage, indicated significant differences $(p<0.05)$ between the ponds within each age group. This showed that the pond effect need to be included in the analysis model as a fixed effect.
Table 4. Heritability estimates for body weight and maternal effects $( \pm \mathrm{SE})$

\begin{tabular}{lll}
\hline Age in days & $h^{2}$ & $h_{m}^{2}$ \\
\hline 210 & $0.32 \pm 0.18$ & $0.08 \pm 0.08$ \\
450 & $0.37 \pm 0.19$ & $0.03 \pm 0.08$ \\
720 & $0.12 \pm 0.05$ & $8.89 \mathrm{E}-8$ \\
830 & $0.22 \pm 0.07$ & $2.40 \mathrm{E}-7$
\end{tabular}

$h^{2}$ : trait heritability; $h_{m}^{2}$ : the maternal effect

There are numerous reports on the heritability estimates for growth related traits of cultured fish. The heritability estimates in the present study ranged from 0.12 to 0.37 which is comparable to those reported by Navarro et al.

Table 2. Summary of measurement for $P$. olivaceus at four different ages

\begin{tabular}{|c|c|c|c|c|c|c|c|c|}
\hline \multirow{2}{*}{ Age in days } & \multirow{2}{*}{ No. of family } & \multicolumn{2}{|c|}{ Sample no. from families } & \multirow{2}{*}{ No. of records } & \multirow{2}{*}{ Min. (g) } & \multirow{2}{*}{ Max. (g) } & \multirow{2}{*}{ Mean $( \pm \mathrm{SE})$} & \multirow{2}{*}{ C.V. $(\%)$} \\
\hline & & Minimum & Maximum & & & & & \\
\hline 210 & 30 & 45 & 50 & 1450 & 12.8 & 220.0 & $83.46 \pm 0.60$ & 45.72 \\
\hline 450 & 30 & 40 & 50 & 1305 & 12.2 & 362.2 & $171.07 \pm 1.12$ & 34.16 \\
\hline 720 & 30 & 35 & 50 & 1336 & 101.6 & 923.4 & $413.74 \pm 3.55$ & 31.73 \\
\hline 830 & 30 & 28 & 48 & 1292 & 120.4 & 1307.2 & $599.64 \pm 4.62$ & 28.05 \\
\hline
\end{tabular}

Table 3. The descriptive statistics for body weight in each pond at four different ages

\begin{tabular}{|c|c|c|c|c|c|c|}
\hline \multirow{2}{*}{ Age in days } & \multirow{2}{*}{ Pond } & \multirow{2}{*}{ Number } & \multicolumn{4}{|c|}{ Body weight (g) } \\
\hline & & & Min. & Max. & Mean $( \pm \mathrm{SE})^{*}$ & C.V. $(\%)$ \\
\hline \multirow[t]{2}{*}{210} & 1 & 655 & 12.9 & 220.0 & $89.88 \pm 0.91^{\mathrm{a}}$ & 43.35 \\
\hline & 2 & 795 & 12.8 & 215.7 & $78.17 \pm 0.78^{b}$ & 46.90 \\
\hline \multirow[t]{2}{*}{450} & 1 & 581 & 12.2 & 362.1 & $207.88 \pm 1.31^{\mathrm{a}}$ & 21.90 \\
\hline & 2 & 724 & 19.5 & 362.2 & $141.54 \pm 1.29^{b}$ & 35.55 \\
\hline \multirow[t]{3}{*}{730} & 1 & 485 & 172.4 & 923.4 & $496.08 \pm 5.51^{\mathrm{a}}$ & 24.63 \\
\hline & 2 & 382 & 238.8 & 736.0 & $458.26 \pm 3.87^{b}$ & 16.80 \\
\hline & 3 & 469 & 101.6 & 546.0 & $292.34 \pm 3.35^{\mathrm{c}}$ & 25.36 \\
\hline \multirow[t]{3}{*}{830} & 1 & 450 & 226.2 & 1307.2 & $654.73 \pm 7.03^{\mathrm{a}}$ & 22.79 \\
\hline & 2 & 380 & 267.2 & 1251.4 & $701.67 \pm 7.03^{b}$ & 19.95 \\
\hline & 3 & 462 & 120.4 & 777.2 & $462.06 \pm 4.76^{c}$ & 22.64 \\
\hline
\end{tabular}

"Comparison of the mean values of body weight between ponds in each stage. Means bearing different superscripts are significantly different $(\mathrm{p}<0.05)$

\section{Heritability estimation}

Determination of the heritability for economically important traits provides the foundation for designing suitable breeding programme. Variance components, heritability of body weight $\left(h^{2}\right)$ and heritability of maternal effect $\left(h_{m}^{2}\right)$ were estimated (Table 4$)$. The heritability for body weight ranged from 0.12 to 0.37 , showing a large variation. The heritability of body weight at 720 days of age (0.12) was less than those of the other three ages. One of the probable reasons is that 720 days of age $P$. olivaceus were in a stage of overwintering with low - temperature environment, and were in a state of growth arrest. Additionally, the estimated heritability at the first growth spurt (450 days of age) was larger than that of the second growth spurt (830 days of age), which indicated that heritability estimates in the early growing stage of fish were higher than that in the later stages under the same conditions.
(2009). Whatmore et al. (2013) for body and carcass traits in Seriola lalandi (0.15 to 0.30). Gjerde et al. (2012) estimated the heritability of body weight in Oreochromis niloticus $(0.19 \pm 0.04)$, which was higher than thepresent estimate at 720 days of age (0.12) but lower than those for the other three ages $(0.22-0.37)$ obtained in the present study. In the study of Shimada et al. (2007), the estimates of heritability for body weight in progeny from wild caught and repeatedly crossbred P. olivaceus broodfish were 0.499 and 0.385 , respectively. Tian et al. (2011) also reported estimates of heritability in P. olivaceus as $0.48 \pm 0.04$ for body weight at 8 months of age. In this study, the estimates of heritability for body weight at the four different ages $(0.12-0.37)$ were somewhat lower compared to the above two reports. The observed differences could be attributed to the different statistical model used and method of parameter estimation as well as the difference 
in the sample size and data structure, as reported by Zhang et al. (2014).

Maternal effect was present during the first two ages ( 0.08 and 0.03 respectively), whereas these effects were not discernible at the latter two growing stages, which were different from the value of maternal effect $(0.07-0.54)$ obtained by Liu et al. (2011). This is as expected because as the fish grows, the maternal influence diminishes. Therefore, maternal effect would be important and should be considered while evaluating growth traits during early life stages of P. olivaceus.

\section{Correlation analysis}

ASReml software can estimate variance components in addition to solving mixed linear model equations to predict EBV for body weight of all individuals. The fish used as broodstock in a breeding program should be selected from the highest ranked breeding value of candidates (Luan et al., 2012). Therefore, it is of crucial importance that the individual breeding value should be predicted as accurately as possible. There are two principal factors which impact the accuracy of EBVs: the amount of the available information on relatives of the candidate and the statistical method used to predict the EBV. The correlation between EBV and phenotypic value (PV) is regarded as an important index in measuring EBV prediction accuracy. Hence, these correlations were calculated and are presented in Table 5. The correlation between PV and EBV at all the four ages ranged from 0.470 to 0.803 and there was no definite trend visible.

The correlation between PV and EBV of body weight at 210 days of age ( 0.803$)$ was the highest among the four ages and that of 720 days of age (0.470) was the lowest, which indicated that the third age (during overwintering) was not an appropriate stage to carry out genetic evaluation and selection of broodstocks. Additionally, all the correlations between EBV and PV of body weight were highly significant at all the four ages $(p<0.01)$. The correlation between EBV and PV fluctuated between the four ages $(0.470-0.803)$, indicating that the prediction accuracy of breeding value was different between different stages. These estimates are lower than the estimates by Zhang et al. (2011), who reported genetic correlations of 0.732 - 0.971 between EBV and PV of body mass in shrimp, Fenneropenaeus chinensis. Among the four ages, the correlation between PV and EBV at 720 days of age (0.470) was obviously less than those of the other three ages, due to the comparatively low heritability of body weight, from which it can be inferred that selection of broodstock carried out in the growth arrest stage is unsuitable.

Table 5 depicts the correlation of the family breeding values among the four ages for body weight (off-diagonal). A large difference of 0.339-0.811 was observed among the estimates of correlation. They were highly significant $(\mathrm{p}<0.01)$, except the correlation between 210 and 830 days of age. The correlation coefficient of the first age and its adjacent age (0.811) is higher than those of the rest $(0.569$ and 0.339 ) of the ages, which suggested the growth at one stage is correlated to its previous one.

Table 5. The family breeding value - correlation among the four stages of the body weight and the correlations of estimated breeding value and phenotypic value in the four stages ${ }^{\text {a }}$

\begin{tabular}{lllll}
\hline Age in days & 210 & 450 & 720 & 830 \\
\hline 210 & $0.803^{* *}$ & & & \\
450 & $0.811^{* *}$ & $0.705^{* *}$ & & \\
720 & $0.569^{* *}$ & $0.636^{* *}$ & $0.470^{* *}$ & \\
830 & 0.339 & $0.564^{* *}$ & $0.612^{* *}$ & $0.569^{* *}$ \\
\hline
\end{tabular}

${ }^{a}$ The diagonal in the table are the correlation coefficients of the estimated breeding value and phenotypic value and the lower triangles for the body weight; ${ }^{* *}$ Correlation is significant at 0.01 level $(2$ - tailed $)$.

This study used only the information from parents and their F1 generation, which are not optimal data as far as the data structure for genetic analysis is concerned. Therefore, additional information (i.e. data from other generations, collateral relatives) should be collected and used in order to increase the accuracy and precision of the estimation for the genetic parameters.

\section{Acknowledgements}

This study was funded by National Natural Science Foundation of China, Taishan Scholar Climbing Project of Shandong Province in China and Startup Foundation for Doctors of Zhejiang Ocean University under contract.

\section{References}

Bentsen, H. B., Gjerde, B., Nguyen, N. H., Rye, M., Ponzoni, R. W., Palada de Vera, M. S., Bolivar, H. L., Velasco, R. R., Danting, J. C., Dionisio, E. E., Longalong, F. M., Reyes, R. A., Abella, T. A., Tayamen, M. M. and Eknath, A. E. 2012. Genetic improvement of farmed tilapias: Genetic parameters for body weight at harvest in Nile tilapia (Oreochromis niloticus) during five generations of testing in multiple environments. Aquaculture, 338-341: 56-65.

Blonk, R. J., Komen, H., Kamstra, A. and van Arendonk, J. A. 2010. Effects of grading on heritability estimates under commercial conditions: A case study with common sole, Solea solea. Aquaculture, 300: 43-49.

Charo-Karisa, H., Bovenhuis, H., Rezk, M. A., Ponzoni, R. W., van Arendonk, J. A. and Komen, H. 2007. Phenotypic and genetic parameters for body measurements, reproductive traits and gut length of Nile tilapia (Oreochromis niloticus) selected for growth in low-input earthen ponds. Aquaculture, 273: 1523.

Das Mahapatra, K., Saha, J. N., Sarangi, N., Jana, R. K., Gjede, B., Nguyen, N. H., Khaw, H. L. and Ponzoni, R. W. 2007. Genetic 
improvement and dissemination of rohu (Labeo rohita, Ham.) in India. Proc. Assoc. Advmt. Anim. Breed. Genet., 17: 37-40.

Fan, L., Jiang, J., Gao, J., Song, H., Liu, J., Yang, L., Li, Z., Chen, Y., Zhang, Q. and Wang, X. 2015. Identification and characterization of a PRDM14 Homolog in Japanese flounder (Paralichthys olivaceus). Int. J. Molecular Sci., 16(5): 9097-9118

Gheyas, A. A., Woolliams, J. A., Taggart, J. B., Sattar, M. A., Das, T. K., McAndrew, B. J. and Penman, D. J. 2009. Heritability estimation of silver carp (Hypophthalmichthys molitrix) harvest traits using microsatellite based parentage assignment. Aquaculture, 294: 187-193.

Gilmour, A. R., Gogel, B. J., Cullis, B. R., Thompson, R., Butler, D., Cherry, M., Collins, D., Dutkowski, G., Harding, S. and Haskard, K. 2012. ASReml user guide release 4.0. VSN International Ltd, Hemel Hempstead, UK.

Gjerde, B., Mengistu, S. B., Odegard, J., Johansen, H. and Altamirano, D. S. 2012. Quantitative genetics of body weight, fillet weight and fillet yield in Nile tilapia (Oreochromis niloticus). Aquaculture, 342: 117-124.

Guy, D. R., Bishop, S. C., Woolliams, J. A. and Brotherstone, S. 2009. Genetic parameters for resistance to Infectious Pancreatic Necrosis in pedigreed Atlantic salmon (Salmo salar) post-smolts using a reduced animal model. Aquaculture, 290: 229-235

He, J., Gao, H., Xu, P. and Yang, R. 2015. Genetic parameters for different growth scales in GIFT strain of Nile tilapia (Oreochromis niloticus). J. Anim. Breed. Genet., p. 1-8.

Hu, G., Gu, W., Bai, Q. L. and Wang, B. Q. 2013. Estimation of genetic parameters for growth traits in a breeding program for rainbow trout (Oncorhynchus mykiss) in China. Genet. Mol. Res., 12(2): 1457-1467.

Karahan, B., Chatain, B., Chavanne, H., Vergnet, A., Bardon, A., Haffray, P., Dupont-Nivet, M. and Vandeputte, M. 2013. Heritabilities and correlations of deformities and growth related traits in the European seabass (Dicentrarchus labrax, L) in four different sites. Aquac. Res., 44(2): 289-299.

Liu, F., Chen, S. L., Wang, L., Tian, Y. S., Deng, H., Liu, S. T., and Sun, D. Q. 2013. Analysis of growth performance and breeding value of Japanese flounder and selection of parents. J. Fish. Sci. China, 20(3): 521-527 (In Chinese)

Liu, X. D., Zhao, G. T., Cai, M. Y. and Wang, Z. Y. 2013. Estimated genetic parameters for growth related traits in large yellow croaker Larimichthys crocea using microsatellites to assign parentage. J. Fish Biol., 82(1): 34-41.

Liu, Y., Chen, S. and Li, B. 2005a. Assessing the genetic structure of three Japanese flounder (Paralichthys olivaceus) stocks by microsatellite markers. Aquaculture, 243: 103-111.

Liu, Y. G., Chen, S. L., Li, B. F., Wang, Z. J. and Liu, Z. 2005 b. Analysis of genetic variation in selected stocks of hatchery flounder Paralichthys olivaceus, using AFLP markers. Biochem. System.Ecol., 33: 993-1005.
Liu, Y. X., Wang, G. X., Wang, Y. F., Si, F., Sun, Z. H., Zhang, X. Y., Wang, J. D. and Liu, H. J. 2011. Estimation of genetic parameters for growth traits of Japanese flounder Paralichthys olivaceus using an animal model. Fish Sci., 77: 87-93.

Luan, S., Yang, G., Wang, J., Luo, K., Zhang, Y., Gao, Q., Hu, H and Kong, J. 2012. Genetic parameters and response to selection for harvest body weight of the giant freshwater prawn Macrobrachium rosenbergii. Aquaculture, 362-363: 88-96.

Navarro, A., Zamorano, M. J., Hildebrandt, S., Gines, R., Aguilera, C. and Afonso, J. M. 2009. Estimates of heritabilities and genetic correlations for growth and carcass traits in gilthead seabream (Sparus auratus L.), under industrial conditions. Aquaculture, 289: 225-230.

Ninh, N. H., Ponzoni, R. W., Nguyen, N. H., Woolliams, J. A., Taggart, J. B., McAndrew, B. J. and Penman, D. J. 2011 A comparison of communal and separate rearing of families in selective breeding of common carp (Cyprinus carpio): Estimation of genetic parameters. Aquaculture, 322-323: 39-46.

Sae-Lim, P., Komen, H., Kause, A., Martin, K. E., Crooijmans, R., van Arendonk, J. A. and Parsons, J. E. 2013. Enhancing selective breeding for growth, slaughter traits and overall survival in rainbow trout (Oncorhynchus mykiss). Aquaculture, 372: 89-96.

SAS 2005. SAS/STAT Software: Version 9.1.3 (TS1M3) for Microsoft Windows. SAS Institute, Cary, NC, USA.

Shao, C., Niu, Y., Rastas, P., Liu, Y., Xie, Z., Li, H., Wang, L., Jiang, Y., Tai, S., Tian, Y., Sakamoto, T. and Chen, S. 2015. Genome-wide SNP identification for the construction of a high-resolution genetic map of Japanese flounder (Paralichthys olivaceus): applications to QTL mapping of Vibrio anguillarum disease resistance and comparative genomic analysis. DNA Res., 22(2): 161-170.

Shimada, Y., Murakami, N., Tsuzaki, T. and Seikai, T. 2007. Changes in growth, higher salinity tolerance and behavioural traits in Japanese flounder Paralichthys olivaceus after repeated cross breeding. Fish. Sci., 73: 364-370.

Song, W. T., Pang, R. Y., Niu, Y. Z., Gao, F. T., Zhao, Y. W., Zhang, J., Sun, J., Shao, C. W., Liao, X. L., Wang, L., Tian, Y. S. and Chen, S. L. 2012. Construction of high-density genetic linkage maps and mapping of growth related quantitative trail loci in the Japanese flounder (Paralichthys olivaceus). PLoS One, 7(11): e50404.

Thodesen, J., Rye, M., Wang, Y. X., Yang, K. S., Bentsen, H. B. and Gjedrem, T. 2011. Genetic improvement of tilapias in China: Genetic parameters and selection responses in growth of Nile tilapia (Oreochromis niloticus) after six generations of multi-trait selection for growth and fillet yield. Aquaculture, 322-323: 51-64.

Tian, Y., Xu, T., Liang, Y. and Chen, S. 2011. Estimates of genetic and phenotypic parameters for weight and length in Paralichthys olivaceus (Temminck et Schlegel). Acta Oceanologica Sinica, 30: 58-64. 
Trọng, T. Q., Mulder, H. A., van Arendonk, J. A. and Komen, H. 2013. Heritability and genotype by environment interaction estimates for harvest weight, growth rate, and shape of Nile tilapia (Oreochromis niloticus) grown in river cage and VAC in Vietnam. Aquaculture, 384: 119-127.

Whatmore, P., Nguyen, N. H., Miller, A., Lamont, R., Powell, D., D'Antignana, T., Bubner, E., Elizur, A. and Knibb, W. 2013. Genetic parameters for economically important traits in yellowtail kingfish Seriola lalandi. Aquaculture, 400: 77-84.

Yang, C. G., Wang, X. L., Zhang, B., Sun, B., Liu, S. S. and Chen, S. L. 2013. Screening and analysis of PoAkirin1 and two related genes in response to immunological stimulants in the Japanese flounder (Paralichthys olivaceus). BMC Mol. Biol., 14(1): 10.

Zhang, T., Kong, J., Luan, S., Wang, Q., Luo, K. and Tian, Y. 2011. Estimation of genetic parameters and breeding values in shrimp Fenneropenaeus chinensis using the REML/BLUP procedure. Acta Oceanologica Sinica, 30: 78-86.

Zhang, Y., Wang, Z., Lei, H., Wang, Z., Su, R., Zhang, W., Zhou, J., Wei, Y., Meng, R., Wang, R. and Li, J. 2014. Estimates of genetic parameters and genetic changes for fleece traits in Inner Mongolia cashmere goats. Small Ruminant Res., 117(1): 41-46. 